\title{
Overexpression of TG2 enhances the differentiation of ectomesenchymal stem cells into neuron-like cells and promotes functional recovery in adult rats following spinal cord injury
}

\author{
WENTAO SHI $^{1 *}$, YUNDUAN QUE $^{1 *}$, DEMIN LV ${ }^{2 *}$, SHIQI BI ${ }^{2}$, \\ ZHONGHUA XU ${ }^{1}$, DONGMIN WANG ${ }^{1,2}$ and ZHIJIAN ZHANG ${ }^{2}$ \\ ${ }^{1}$ Department of Orthopedics, Gaochun People's Hospital of Nanjing, Nanjing, Jiangsu 211300; \\ ${ }^{2}$ Department of Embryology, School of Medicine, Jiangsu University, Zhenjiang, Jiangsu 212001, P.R. China
}

Received December 26, 2018; Accepted May 31, 2019

DOI: $10.3892 / \mathrm{mmr} .2019 .10502$

\begin{abstract}
Ectomesenchymal stem cells (EMSCs) represent a type of adult stem cells derived from the cranial neural crest. These cells are capable of self-renewal and have the potential for multidirectional differentiation. Tissue transglutaminase type 2 (TG2) is a ubiquitously expressed member of the transglutaminase family of $\mathrm{Ca}^{2+}$-dependent crosslinking enzymes. However, the effect of TG2 on neural differentiation and proliferation of EMSCs remains unknown. To determine whether TG2 improves EMSC proliferation and neurogenesis, a stable TG2-overexpressing EMSC cell line (TG2-EMSCs) was established by using an adenovirus system. Immunofluorescence staining and western blot analyses demonstrated that TG2 overexpression had beneficial effects on the rate of EMSC neurogenesis, and that the proliferative capacity of TG2-EMSCs was higher than that of controls. Furthermore, the results of western blotting revealed that extracellular matrix (ECM) and neurotrophic factors were upregulated during the differentiation of TG2-EMSCs. Notably, TG2-EMSC transplantation in an animal model of spinal cord injury (SCI), TG2-EMSCs differentiated into neuron-like cells and enhanced the repair of SCI. Taken together, these results demonstrated that TG2 gene transfection may offer a novel strategy to enhance EMSC proliferation and neurogenesis in vivo and in vitro, which may ultimately facilitate EMSC-based transplantation therapy in patients with SCI.
\end{abstract}

Correspondence to: Professor Dongmin Wang or Professor Zhijian Zhang, Department of Embryology, School of Medicine, Jiangsu University, 301 Xuefu Road, Jing Kou, Zhenjiang, Jiangsu 212001, P.R. China

E-mail: dongmingw59@163.com

E-mail: zzj@ujs.edu.cn

*Contributed equally

Key words: ectomesenchymal stem cells, transglutaminase type 2, spinal cord injury, differentiation

\section{Introduction}

Increasing evidence has revealed that stem cells can express neural cell markers and improve neurological function when transplanted into animal models of spinal cord injury (SCI) $(1,2)$. In particular, mesenchymal stem cells (MSCs) have emerged as one of the most promising types of stem cells due to favorable ethical considerations and improved safety (3). Notably, ectomesenchymal stem cells (EMSCs), which are derived from the cranial neural crest and isolated from the nasal septum, are capable of self-renewal, possess the potential for multi-directional differentiation, and have a strong propensity to differentiate into neurons, and osseous and glial cells (4). A previous study from our laboratory demonstrated that EMSCs transplanted into a rat model of SCI can reduce the functional deficits associated with SCI and promote histological reconstruction in the injured spinal cords of rats and behavioral recovery from an SCI (5). Since EMSCs can be easily isolated from the nasal septa of adult donors without invasive surgery, EMSCs represent a promising type of stem cell for the treatment of SCI (6). However, the use of EMSCs in tissue regeneration has been limited, due to their low proliferation rate, limited lifespan and the progressive loss of their stem cell properties during in vitro expansion $(7,8)$.

Transglutaminase type 2 (TG2) is a unique member of the transglutaminase family of $\mathrm{Ca}^{2+}$-dependent crosslinking enzymes $(9,10)$. An increasing body of evidence from the past decade has revealed that TG2 has multiple and complex activities at the cell surface and within the extracellular matrix (ECM). In particular, TG2 has a crucial role in the regulation of cell-ECM interactions and in outside-in signaling via several types of transmembrane receptor (11). In addition, a number of studies reported that TG2 has important enzymatic and non-enzymatic functions, including the modulation of cell interactions with the ECM and soluble growth factors via non-covalent interactions with, and regulation of, integrins and growth factor receptors $(12,13)$. Furthermore, TG2 can also act as an adhesion receptor for fibronectin (FN) and laminin (LN) at the cell surface, including vascular smooth muscle cells, connective tissue fibroblasts, osteoblasts, neurons and astrocytes (11). To the best of our knowledge, TG2 is 
involved in numerous processes, including cellular differentiation, apoptosis, adhesion and matrix assembly $(14,15)$. In particular, it has been demonstrated that TG2 is associated with cell differentiation in neurons and astrocytes, and that it is crucial for neuronal differentiation in human neuroblastoma SH-SY5Y cells (16). Although biochemical and biological responses induced by TG2 on primary cultured cells or established cell lines have been extensively studied $(17,18)$, little is currently known regarding TG2 effects on EMSCs undifferentiated cells.

To determine whether TG2 expression could improve EMSC proliferation and neurogenesis, the present study investigated the biological mechanism involved in the effects of TG2 on the proliferation, migration and differentiation of EMSCs isolated from the nasal septum of rats. The therapeutic effects of transplanting TG2-transfected EMSCs in rats following SCI were subsequently investigated.

\section{Materials and methods}

Isolation and expansion of rat EMSCs. EMSCs were isolated following the protocol described in our previous study (10). Briefly, two female Sprague-Dawley (SD) rats (weight, $120 \mathrm{~g}$; provided by Jiangsu University Animal Center) were sacrificed by intraperitoneal injection of pentobarbital sodium overdose $(200 \mathrm{mg} / \mathrm{kg})$. Subsequently, nasal septum mucosa tissue samples were collected from the lower third of the rat nasal septum (4). These mucous membranes were gently minced into pieces $\left(0.5-1 \mathrm{~mm}^{3}\right)$. and cultured in Dulbecco's modified Eagle's medium/nutrient mixture F12 (Hyclone; GE Healthcare Life Sciences) containing $10 \%$ fetal bovine serum (FBS; GIBCO; Thermo Fisher Scientific, Inc.) and penicillin-streptomycin $(100 \mathrm{U} / \mathrm{ml})$ and placed at $37^{\circ} \mathrm{C}$ in a humidified incubator containing $5 \% \mathrm{CO}_{2}$. After seven days, medium was replaced and non-adherent cells were removed. Spindle-shaped adherent EMSCs were expanded and purified via three passages following the initial seeding. Medium was then replaced and cells were observed with an inverted phase contrast microscope every three days. After 14 days, spindle-shaped adherent EMSCs were harvested using $0.25 \%$ trypsin and subcultured until they reach $80-90 \%$ confluence. EMSCs (passage 3) were identified by detecting the expression of nestin (rabbit polyclonal, ab27952, Abcam), vimentin (mouse monoclonal; cat. no. BM0135; Wuhan Boster Biological Technology, Ltd.; 1:400), CD133 (rabbit polyclonal; cat. no. BA3993-2; Wuhan Boster Biological Technology, Ltd.; 1:400) and CD44 (rabbit polyclonal; cat. no. A00052; Wuhan Boster Biological Technology, Ltd.; 1:400) by immunofluorescence staining according to the protocol described in the following section.

Immunofluorescence staining. Cells were fixed with $4 \%$ paraformaldehyde (PFA) for $30 \mathrm{~min}$ at $4^{\circ} \mathrm{C}$ and then washed three times with PBS and treated with PBS containing $0.3 \%$ Triton X-100 and 3\% bovine serum albumin (Beijing Solarbio Science \& Technology Co., Ltd.) for $20 \mathrm{~min}$ at room temperature. Following another round of washing with PBS, cells were incubated with the aforementioned primary antibodies against nestin, vimentin, CD133 and CD 44 at $37^{\circ} \mathrm{C}$ for $3 \mathrm{~h}$. Cells were washed three times with PBS and were incubated with the corresponding secondary antibodies, including Alexa Fluor 488/Cy3-conjugated goat anti-mouse/rabbit immunoglobulin (Ig)G Cy3-labeled goat anti-mouse/rabbit IgG (1:200; cat. no. C5838/C2821 Sigma-Aldrich; Merck KGaA) and Alexa Fluor 488-conjugated goat anti-mouse IgG (1:200; cat. no. SAB4600388; Sigma-Aldrich; Merck KGaA) at $37^{\circ} \mathrm{C}$ for $2 \mathrm{~h}$. The nuclei were counterstained with DAPI $(0.5 \mu \mathrm{g} / \mathrm{ml}$; Sigma-Aldrich; Merck KGaA) at room temperature for $10 \mathrm{~min}$ and cells were observed under an immunofluorescence microscope (magnification, x100 or x200).

Hematoxylin and eosin staining. After 8 weeks, the rats were sacrificed by deep anesthetization with an intraperitoneal injection of phenobarbital sodium $(200 \mathrm{mg} / \mathrm{kg})$, and fresh spine cord were fixed in $4 \%$ paraformaldehyde overnight at $4^{\circ} \mathrm{C}$. After dehydration in a graded series of ethanol solutions, the tissue was embedded in paraffin. Serial longitudinal tissue sections were prepared and subjected to staining and observation as follows. The spine cord specimens were cut into $10-\mu \mathrm{m}$ sections, which were stained with hematoxylin and eosin at room temperature for $30 \mathrm{~min}$ to evaluate the repair effects.

Construction of recombinant adenoviruses. The following primers were designed to synthesize the TG2 gene (2061 base pairs): TG2, forward 5'-CTAGCTAGCGCCACCatg gccgaggagctgaacct-3' and rTG2, reverse, 5'-GGAATTCttagg ccgggecgatgatga-3'. A recombinant rat TG2(rTG2) adenovirus shuttle plasmid was constructed by Nanjing Genscript Bioengineering Technology and Services Co., Ltd. and confirmed by sequencing. Briefly, TG2 genes were inserted into a pAdShuttle-IRES-hrGFP2-TG2 vector to prepare shuttle vectors, and the pAdShuttle-IRES-hrGFP2 vector was set as a parallel group. Subsequently, 293A cells $\left(2 \times 10^{6}\right.$ cells/well; American Type Culture Collection) were seeded in $6-\mathrm{cm}^{2}$ dishes in DMEM supplemented with $10 \%$ FBS and placed at $37^{\circ} \mathrm{C}$ in a humidified incubator containing $5 \% \mathrm{CO}_{2}$ overnight. The medium was replaced before transfection. The cells were transfected at $80-90 \%$ confluency with pacAd5-9.2-100 $\left(2 \times 10^{8} \mathrm{TU} / \mathrm{ml}\right)$ and the pAdShuttle-IRES-hrGFP2-TG2 $\left(4 \times 10^{8} \mathrm{TU} / \mathrm{ml}\right)$ shuttle plasmid using Lipofectamine 2000 ä (Invitrogen; Thermo Fisher Scientific, Inc.) according to the manufacturer's instructions. Following 12 days of transfection, recombinant adenoviruses harboring the GFP positive cells were selected and TG2 (Ad-TG2-GFP) gene were harvested. All recombinant adenoviruses were amplified in 293A cells and purified using double cesium chloride density gradient ultracentrifugation $\left(4^{\circ} \mathrm{C}, 12,000 \mathrm{~g}, 2.5 \mathrm{~h}\right)$. Titers of the adenoviral stocks were determined using a plaque assay in $293 \mathrm{~A}$ cells. EMSCs $\left(2 \times 10^{5}\right)$ at passage three were infected with Ad-TG2-GFP at a multiplicity of infection (MOI) of $10 \mathrm{pfu} / \mathrm{cell}$ following standard infection procedures (19), and the adenovirus with no insert was used as the control (Ad-EMSCs). After $24 \mathrm{~h}$, TG2-GFP-EMSCs (TG2-EMSCs) and Ad-EMSCs were harvested, and TG2-GFP and GFP gene expression was detected using a fluorescence microscope.

Western blot analysis. Protein was detected by western blotting. Briefly, cells were lysed with RIPA buffer (Beijing Solarbio Science \& Technology Co., Ltd.) at $0^{\circ} \mathrm{C}$ for $30 \mathrm{~min}$ 
containing phenylmethylsulfonyl fluoride, a phosphatase inhibitor (Beijing Solarbio Science \& Technology Co., Ltd.) cocktail and EDTA (Beijing Solarbio Science \& Technology Co., Ltd.). The protein concentrations were determined using a BCA kit (Thermo Fisher Scientific, Inc.). Protein $(20 \mu \mathrm{g})$ from each sample was loaded into $8 \%$ polyacrylamide gels, separated by SDS-PAGE, and transferred onto a polyvinylidene difluoride (PVDF) membrane (EMD Millipore) by electrophoresis. Then, membranes were blocked with $3 \%$ skimmed dried milk (dissolved in TBS + Tween-20 (TBST; $20 \mathrm{mM}$ Tris- $\mathrm{HCl}, 150 \mathrm{mM} \mathrm{NaCl} \mathrm{pH} 7.5$ and $0.1 \%$ Tween-20) at $4^{\circ} \mathrm{C}$ for $8 \mathrm{~h}$ and incubated with primary antibodies, including anti-TG2 (1:200; sc-48387, Santa Cruz Biotechnology, Inc.), anti- $\beta$ III Tubulin (1:300; cat. no. ab1827; Abcam), anti-GAP-43 (1:500; cat. no. ab16053; Abcam; 1:300), anti-MAP2 (1:500; cat. no. ab11267; Abcam), anti-NF-200 (1:300; NF-200; cat. no. sc-32729; Santa Cruz Biotechnology, Inc.), anti-BDNF (1:200; cat. no. PB0013; Wuhan Boster Biological Technology, Ltd.), anti-NGF (1:500; cat. no. BA0611-2; Wuhan Boster Biological Technology, Ltd.), anti-FN (1:500; cat. no. BA1772; Wuhan Boster Biological Technology, Ltd.) and anti-LN (1:500; cat. no. BM4921; Wuhan Boster Biological Technology, Ltd.) at $4^{\circ} \mathrm{C}$ for $12 \mathrm{~h}$. Then, membranes were washed with TBS + Tween-20 (TBST; $20 \mathrm{mM}$ Tris- $\mathrm{HCl}$, $150 \mathrm{mM} \mathrm{NaCl} \mathrm{pH} 7.5$ and $0.1 \%$ Tween-20) and incubated with horseradish peroxidase-conjugated secondary antibodies (IgG; 1:10,000; cat. no. ZB-2301; OriGene Technologies, Inc.) or HRP-conjugated goat anti-mouse IgG $(1: 10,000$; cat. no. ZB-2305; OriGene Technologies, Inc.) for $1 \mathrm{~h}$ at $37^{\circ} \mathrm{C}$. Following washing with TBST, bands were detected using enhanced chemiluminescence substrate (Wuhan Boster Biological Technology, Ltd.). $\beta$-actin (1:400; cat. no. BM3873; Wuhan Boster Biological Technology, Ltd.) served as the protein loading control. The protein bands were scanned with Typhoon 9400 Variable Mode Imager (GE Healthcare Life Sciences). Each experiment was repeated at least three times for statistical analysis.

TG2-EMSCs proliferation in vitro. In the present study, Ki-67 immunofluorescence and MTT assay were used to evaluate cell proliferation. TG2-EMSCs, Ad-EMSCs and EMSCs were cultured in 24-well plates at a density of $1 \times 10^{4}$ cells/well and stained by immunofluorescence for Ki-67 (rabbit polyclonal; cat. no. ab15580; Abcam; 1:400) according to the aforementioned procedure; DAPI was used to counterstain the nuclei. Images were captured by fluorescence microscopy (magnification, x200; Eclipse Ti; Nikon Corporation) and the percentage of Ki-67-positive cells were analyzed and calculated with ImageJ software (version 1.51k, National Institutes of Health). The experiment was performed in triplicate, and five visual fields were calculated in each well.

The MTT assay (Beijing Solarbio Science \& Technology Co., Ltd.) was conducted to quantify the proliferative capacity of EMSCs according to the manufacturer's instructions. Briefly, cells were harvested, seeded into 96-well plates at a density of $1 \times 10^{4}$ cells/well and cultured for $1,3,5$ and 7 days. MTT solution $(20 \mu \mathrm{l})$ was then added to each well and incubated at $37^{\circ} \mathrm{C}$ for $2 \mathrm{~h}$. Absorbance was read by a HTS 7000 Plus Bio Assay reader (PerkinElmer, Inc.) at $490 \mathrm{~nm}$. To yield the cumulative doubling levels, the population doubling level of each passage was calculated and then added to the population doubling levels of the previous passages.

Neural differentiation in vitro. The neuronal differentiation assay was performed following our previous work (4). Briefly, cells were seeded into 24 - or 6-well plates at a density of $1 \times 10^{4}$ or $2 \times 10^{5}$ cells/well with neurogenic medium consisting of 10\% FBS (GE Healthcare Life Sciences), 2\% B27 (Gibco; Thermo Fisher Scientific, Inc.), $1 \mu \mathrm{g} / \mathrm{ml}$ ATRA (Merck KGaA), $50 \mathrm{ng} / \mathrm{ml}$ sonic hedgehog (PeproTech, Inc.) and $50 \mathrm{ng} / \mathrm{ml} \mathrm{NT-3}$ (PeproTech, Inc.) and placed at $37^{\circ} \mathrm{C}$ in a humidified incubator containing $5 \% \mathrm{CO}_{2}$ for two weeks; the medium was replaced every three days. These differentiated cells were fixed with $4 \%$ PFA for immunofluorescence staining at $4^{\circ} \mathrm{C}$ for $12 \mathrm{~h}$, digested using a $0.25 \%$ trypsin solution, and washed several times with PBS according to the aforementioned protocol. The primary antibodies were purchased from Chemicon International; Thermo Fisher Scientific, Inc. and comprised of mouse anti- $\beta$ III Tubulin (Tuj-1; rabbit polyclonal; cat. no. ab1827; Abcam; 1:300), mouse anti-growth associated protein-43 (GAP-43; rabbit polyclonal; cat. no. ab16053; Abcam; 1:300), mouse anti-microtubule-associated protein 2 (MAP2; mouse monoclonal; cat. no. ab11267; Abcam; 1:300) and mouse anti-actin (mouse monoclonal; cat. no. BM5422; Wuhan Boster Biological Technology, Ltd.; 1:400).

Neural differentiation in vivo. Adult female SD rats weighing $200 \mathrm{~g}$ were used in the present study and all animal procedures were approved by the Jiangsu University School of Medicine and Gaochun People's Hospital Animal Experiment Committee. Animals were anaesthetized with sodium pentobarbital $(50 \mathrm{mg} / \mathrm{kg}$, intraperitoneal injection) and were subjected to a dorsal laminectomy at T10 to expose the cervical spinal cord (20). Briefly, the dura mater was opened and a spinal resection at the T10 level was performed using iridotomy scissors. After hemostasis, transplanted cells were prepared at a density of $2 \times 10^{5}$ cells $/ \mu 1$ and $5 \mu 1$ of the cell suspension was poured into a fibrin gel in order to prevent cell loss. The fibrin gel containing EMSCs and the fibrin gel without cells (control group) were immediately implanted into a hemisected cavity. Following surgery, rats received extensive care including intramuscular injection of penicillin $(50,000 \mathrm{U} / \mathrm{kg} /$ day $)$ for 3 days and manual emiction twice daily. A total of 18 animals ( $n=6$ in each of the Ad-EMSCs, EMSCs and TG2-EMSC groups) were sacrificed at 4 weeks post-treatment for western blotting and immunofluorescent staining. Firstly, at 4 weeks after SCI (20), three animals in each group were sacrificed with sodium pentobarbital $(200 \mathrm{mg} / \mathrm{kg})$. The spinal cord was carefully isolated, fixed overnight in $4 \%$ PFA at $4^{\circ} \mathrm{C}$, and dehydrated with saturated sucrose (21). Serial longitudinal sections were cut with a cryostat and subjected to staining. Immunofluorescence staining was performed on $15-\mu \mathrm{m}$ spinal cord sections incubated with mouse anti-NF-200 (1:300; NF-200; cat. no. sc-32729; Santa Cruz Biotechnology, Inc.) and anti-Tuj-1 (1:300; Tuj-1; cat. no. ab1827; Abcam) monoclonal antibodies overnight at $4{ }^{\circ} \mathrm{C}$, and with $\mathrm{Cy} 3$-conjugated rabbit anti-mouse IgG (1:200; cat. no. sc-358916; Santa Cruz Biotechnology, Inc.) at $37^{\circ} \mathrm{C}$ for $1 \mathrm{~h}$. Images were captured with a Nikon fluorescence microscope. Secondly, western blotting was performed to analyze NF-200 and MAP2 expression in 


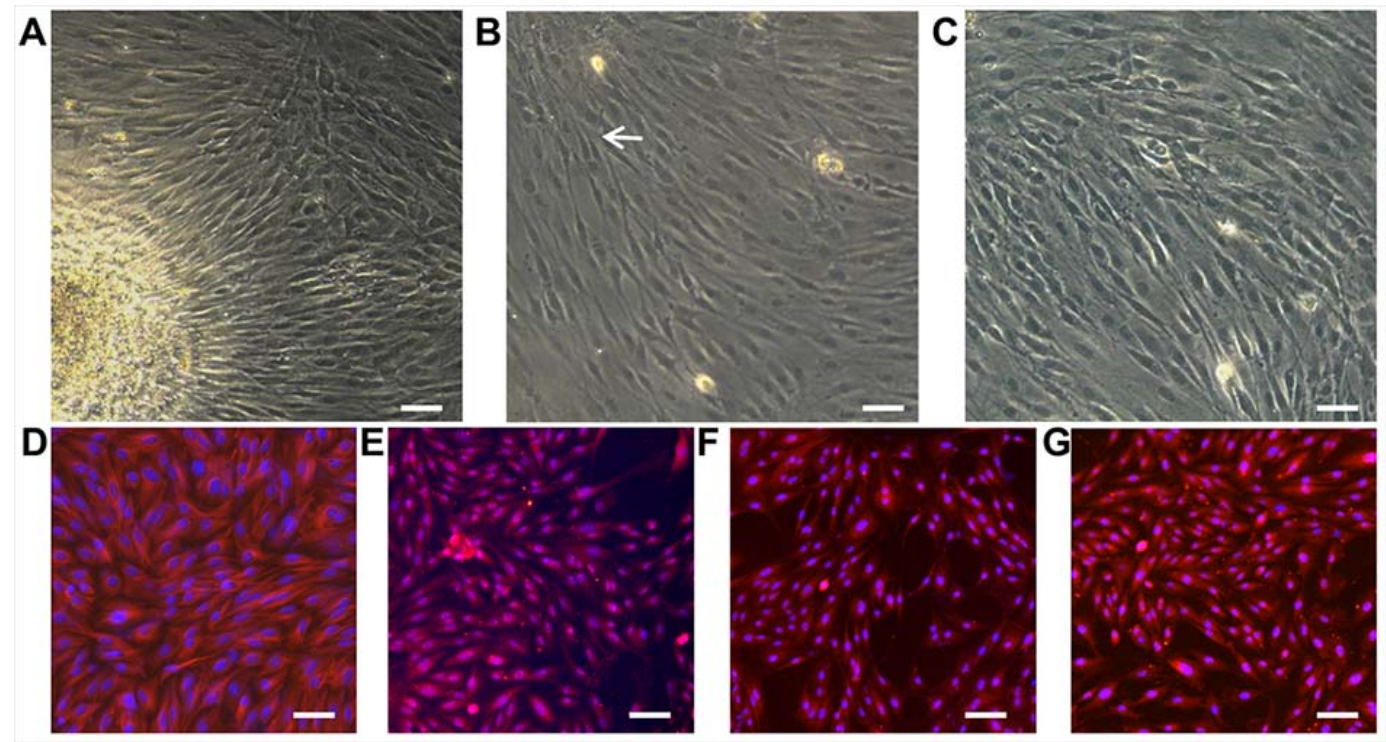

Figure 1. Identification of EMSCs. (A) A representative image of primary EMSCs. Phase-contract images of EMSCs from passages (B) 3 and (C) 5. EMSCs of passage 3 positively expressed neural crest cell and mesenchymal stem cell markers, including (D) vimentin, (E) s100, (F) CD44 and (G) nestin. Scale bar, $50 \mu \mathrm{m}$. EMSCs, ectomesenchymal stem cells.

rats following SCI. Briefly, at the end of the experiment, three animals per group were sacrificed with intraperitoneal injections of an overdose of pentobarbital sodium $(200 \mathrm{mg} / \mathrm{kg})$ and 1-cm-long spinal cord segments containing the lesion center were isolated. For western blotting, the spinal cords were removed and homogenized in SDS sample buffer containing a protease inhibitor cocktail. Protein samples were separated on an $8 \%$ SDS-polyacrylamide gel and transferred onto nitrocellulose membranes according to the aforementioned protocol.

Behavioral assessment. A total of 18 rats $(n=6$ in each of the Ad-EMSCs, EMSC and TG2-EMSC groups) were allowed to survive for eight weeks and were subjected to behavioral assessments. Behavioral tests [Grid-walk and Basso, Beattie, and Bresnahan (BBB) score] were performed on the same set of animals used for the functional recovery analysis $(22,23)$. Animals were pre-trained for 7 days prior to surgery to walk on a grid runway (20x120 cm with $5 \times 5 \mathrm{~cm}$ holes) to receive a food reward. A Grid-walk test was performed 8 weeks post-surgery. At the time of the test, rats were allowed to pass through the grid runway 4 times, which was recorded with a digital camera. The number of paw placement errors (when the hind paw passes through the hole and the knee joint is visible under the grid) and the average number of errors per run and per animal were then calculated. The BBB score was used to evaluate the recovery of neurological function following SCI. Animals were pre-acclimatized to the open field for 7 days prior to surgery. Each animal was given scores on a weekly basis by two observers who were blinded to treatment allocation.

Statistical analysis. All experiments were performed at least twice. Data are expressed as the mean \pm standard deviation. All data were analyzed using SPSS 22.0 statistical software (IBM Corp.). One-way analysis of variance followed by Tukey's post-hoc test was used for multiple comparisons. $\mathrm{P}<0.05$ was considered to indicate a statistically significant difference.

\section{Results}

Morphological characterization and identification of EMSCs. As presented in Fig. 1A, EMSCs migrated out from the lamina propria. After three days, typical spindle-like shaped cells adhered to the surface and formed colonies, which was observed with a high proliferation rate (Fig. 1B). The cell distribution was found to be uniform with a polar shape after fusion and swirling growth (Fig. 1C). Furthermore, EMSCs typically expressed different antigenic markers. Our previous work revealed that the surface markers vimentin, s100, CD44 and nestin can be important antigenic markers for EMSCs (4). To evaluate the cell stemness, antibodies against neural crest and mesenchymal stem cell markers, including vimentin (Fig. 1D), s100 (Fig. 1E), CD44 (Fig. 1F) and nestin (Fig. 1G), were therefore used for immunofluorescent staining. The results demonstrated that EMSCs were positive for those markers, which was consistent with the results from previous reports $(24,25)$. These results suggested that high-purity EMSCs may be harvested simply and efficiently through adherent culture.

Transfection efficiency of adenovirus vector with TG2 in EMSCs. To evaluate the efficiency of TG2 transfection, TG2 expression was evaluated by immunofluorescence and western blotting. As presented in Fig. 2A, following a 48-h transfection with the adenovirus, EMSCs in the transfected group displayed GFP fluorescence, and an abundant grit-like TG2 $(9,10)$ was observed around the visible nucleus under fluorescence microscope (Fig. 2B). This indicated that the TG2 adenovirus had been successfully transfected into EMSCs without any observable cytopathic effects. Western blotting was employed to determine protein expression levels. As presented in Fig. 2C and D, TG2 expression was significantly increased following transfection of adenoviral vector with TG2 in EMSCs, whereas EMSCs and cells transfected with adenoviral vector without TG2 only expressed only a small 

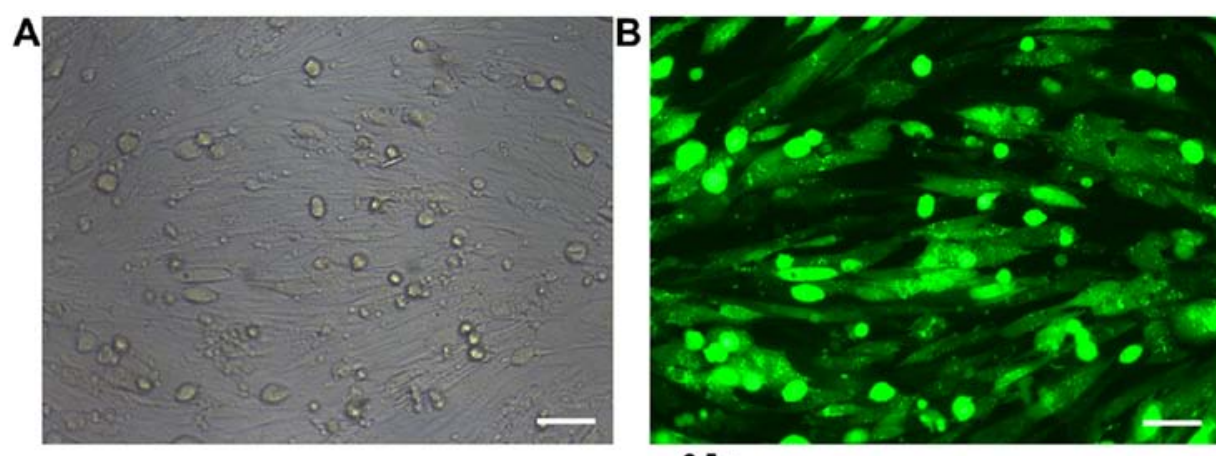

C

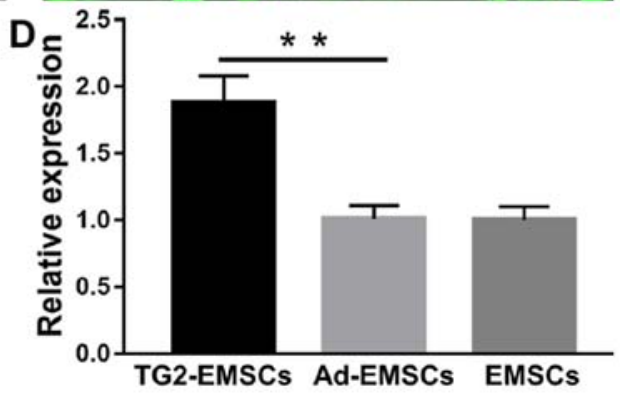

Figure 2. TG2 transduction into EMSCs (TG2-EMSCs) with adenovirus. Adenovirus vectors without TG2 were also constructed and used as controls (Ad-EMSCs=no insert-infected EMSCs). (A) Phase-contract images of TG2-EMSCs. (B) TG2-GFP expression in EMSCs 24 h following TG2-GFP adenovirus transduction. (C) Western blotting of TG2 expression in EMSCs. (D) Quantitative analysis of the expression levels of TG2 relative to the expression level of actin. Data represent the means \pm standard deviation of measurements made from three replicates. ${ }^{* *} \mathrm{P}<0.01$, as indicated. Scale bar, $50 \mu \mathrm{m}$. Ad, adenovirus; EMSCs, ectomesenchymal stem cells; GFP, green fluorescent protein; TG2, transglutaminase type 2.
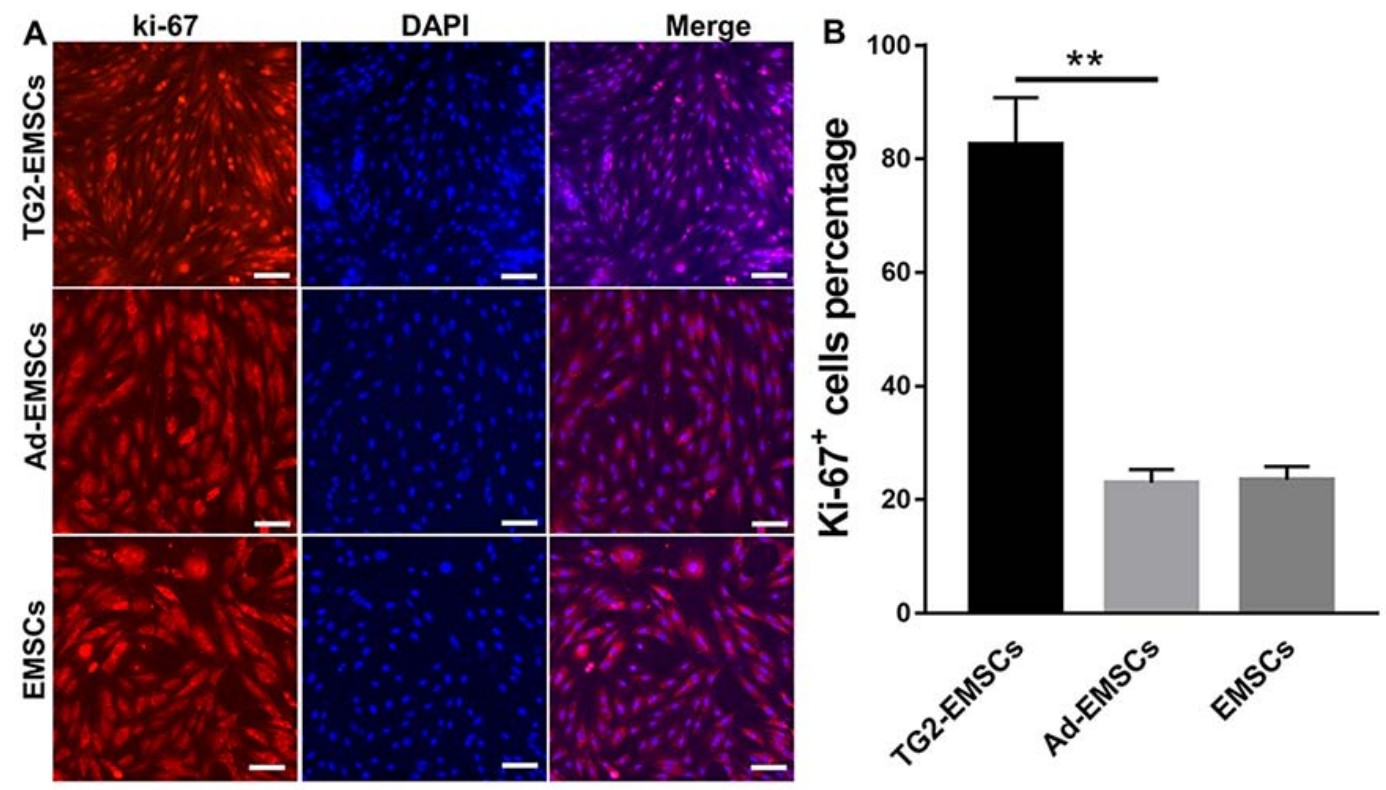

Figure 3. Proliferative capacity of TG2-EMSCs. (A) Ki-67 immunostaining results. (B) Quantification of Ki- $67^{+}$cell percentage ( $\mathrm{n}=3$ ). ${ }^{* *} \mathrm{P}<0.01$, as indicated. Scale bar, $50 \mu \mathrm{m}$. Ad, adenovirus; EMSCs, ectomesenchymal stem cells; TG2, transglutaminase type 2.

amount of TG2. These results indicated that cell transfection with a TG2 adenoviral vector significantly increased TG2 expression in EMSCs.

Proliferative abilities of TG2-EMSCs. Results from Ki-67 immunofluorescent staining demonstrated that the majority of TG2-EMSCs exhibited a high nuclear expression of Ki-67 (Fig. 3A and B). Conversely, Ki-67 expression in the EMSCs and Ad-EMSCs groups was significantly weaker. Furthermore, the results from the MTT assay and the cell count further confirmed that TG2-EMSCs exhibited a better proliferative capacity than the control cells (Fig. 4A and B). Collectively, these data demonstrated that TG2-overexpressing EMSCs may have higher expansive and proliferative capacities than control cells.

Differences in neurogenic differentiation in vitro. Following induction, morphological changes of the differentiated cells 

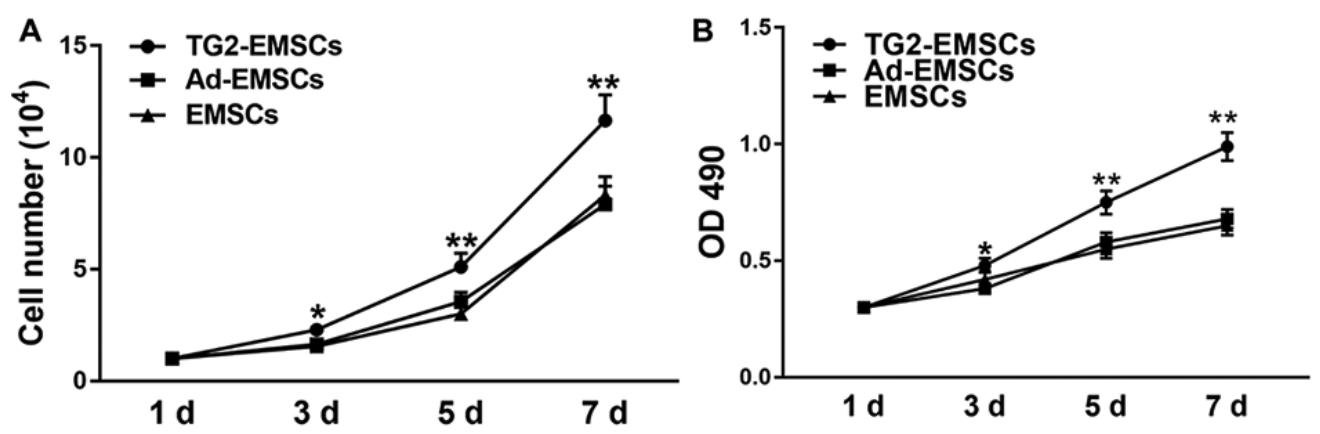

Figure 4. Effect of TG2 on EMSCs proliferation. (A) Results of cell counting and (B) MTT assay ( $\mathrm{n}=5$ ). ${ }^{*} \mathrm{P}<0.05$ and ${ }^{* *} \mathrm{P}<0.01$, as indicated. Ad, adenovirus; EMSCs, ectomesenchymal stem cells; TG2, transglutaminase type 2.
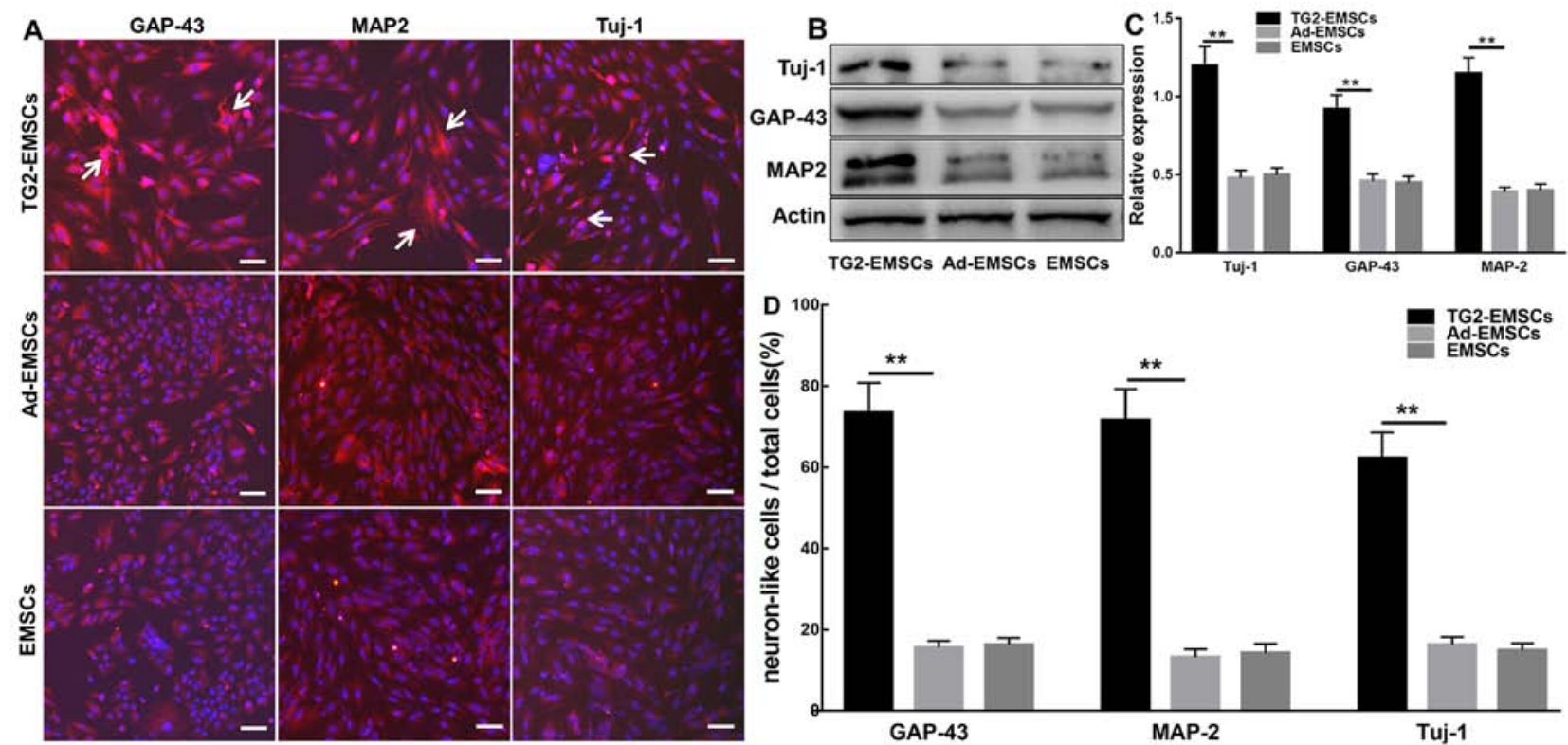

Figure 5. Cells were induced to differentiate into neuronal-like cells following two weeks of culture in neurogenic differentiation media. (A) Representative images of GAP-43, MAP2 and Tuj-1 staining in cells following induction. (B) Representative western blotting images. (C) Western blotting quantification $(n=4)$. (D) Quantitative analysis of cells positive for GAP-43, MAP2 and Tuj-1. Data represent the mean \pm standard error of the mean of samples analyzed in triplicate. ${ }^{* *} \mathrm{P}<0.01$, as indicated. Scale bar, $50 \mu \mathrm{m}$. Ad, adenovirus; EMSCs, ectomesenchymal stem cells; GAP-43, growth associated protein-43; MAP2, microtubule-associated protein 2 ; TG2, transglutaminase type 2 ; Tuj-1, $\beta$ III tubulin.

were observed by inverted phase contrast microscopy. As shown in Fig. 5A, certain cells exhibited neuron-like phenotypes (white arrow). In particular, the cytoplasm in TG2-EMSCs formed a contracted multipolar shape and presented with neuronal morphology, including a small cell body and some long extensions reminiscent of neurons. Conversely, few cells displayed morphological changes in the control groups, which indicated failure of induction. In addition, as presented in Fig. 5A, neuronal markers, including MAP2, GAP-43 and Tuj-1 were used to identify the differentiation of neuronal cells. These neuronal cells expressed myelination-related molecules, such as MAP2, GAP-43 and Tuj-1, more strongly than did the ad-EMSCs and EMSCs. In addition, western blotting demonstrated that MAP2, GAP-43 and Tuj-lexpression levels were significantly increased in TG2-EMSCs (Fig. 5B and C) compared with the control group. Furthermore, significantly higher percentages of TG2-EMSCs were differentiated into GAP- $43^{+}, \mathrm{MAP}^{+}$and Tuj-1 $1^{+}$neuron-like cells compared with the control group (Fig. 5D).
Involvement of ECM and neurotrophic factors in the differentiation of EMSCs. ECM is an important component of the cellular microenvironment and is involved in MSC differentiation (10). In the present study, western blotting was used to examine the effects of TG2 adenovirus transfection on ECM and neurotrophic factors in EMSCs. The results demonstrated that transfection with TG2 adenovirus promoted ECM deposition, including LN and FN, on EMSCs. According to western blotting results, TG2 adenovirus transfection increased the protein levels of neurotrophic factors including nerve growth factor (NGF) and brain derived neurotrophic factor (BDNF) in differentiated EMSCs (Fig. 6).

Axon marker expression and neurogenic differentiation of TG2-EMSCs in vivo. These experiments aimed to assess the effect of TG2 overexpression on the differentiation of transplanted EMSCs in a SCI lesion in rats. Two weeks following transplantation, the TG2-GFP-EMSCs were dispersed in the lesion sites, as observed by immunofluorescent microscopy. 

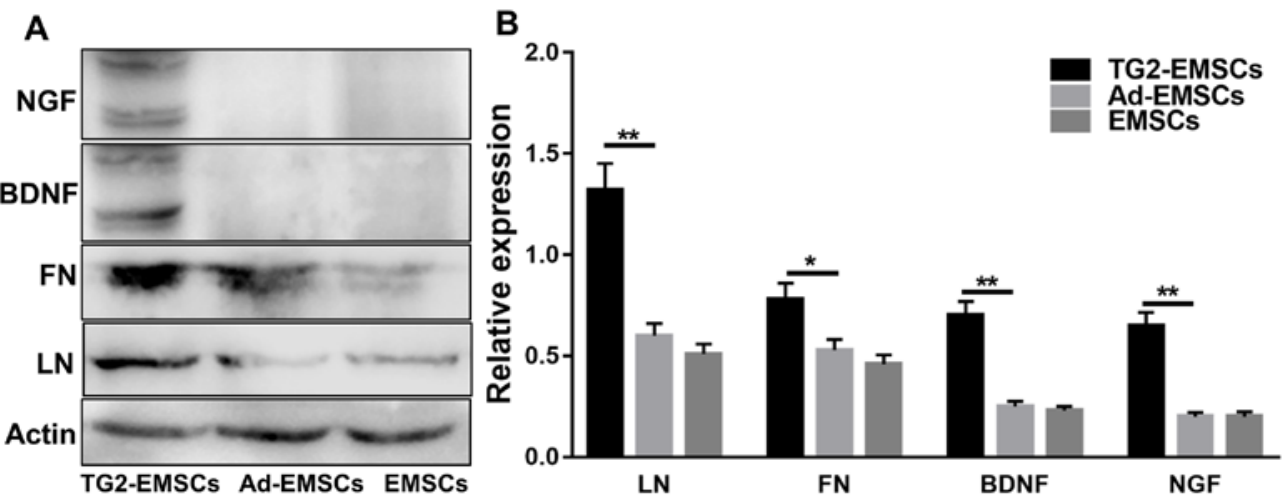

Figure 6. Effects of TG2 adenovirus transfection on the ECM and neurotrophic factors in EMSCs following neural induction. (A) Western blotting of LN, FN BDNF and NGF expression levels (B) Western blotting quantification. Data represent the mean \pm standard deviation of measurements made from three replicates. " $\mathrm{P}<0.05$ and ${ }^{* *} \mathrm{P}<0.01$, as indicated. Ad, adenovirus; BDNF, brain-derived neurotrophic factor; EMSCs, ectomesenchymal stem cells; FN, fibronectin; LN, laminin; NGF, nerve growth factor; TG2, transglutaminase type 2.

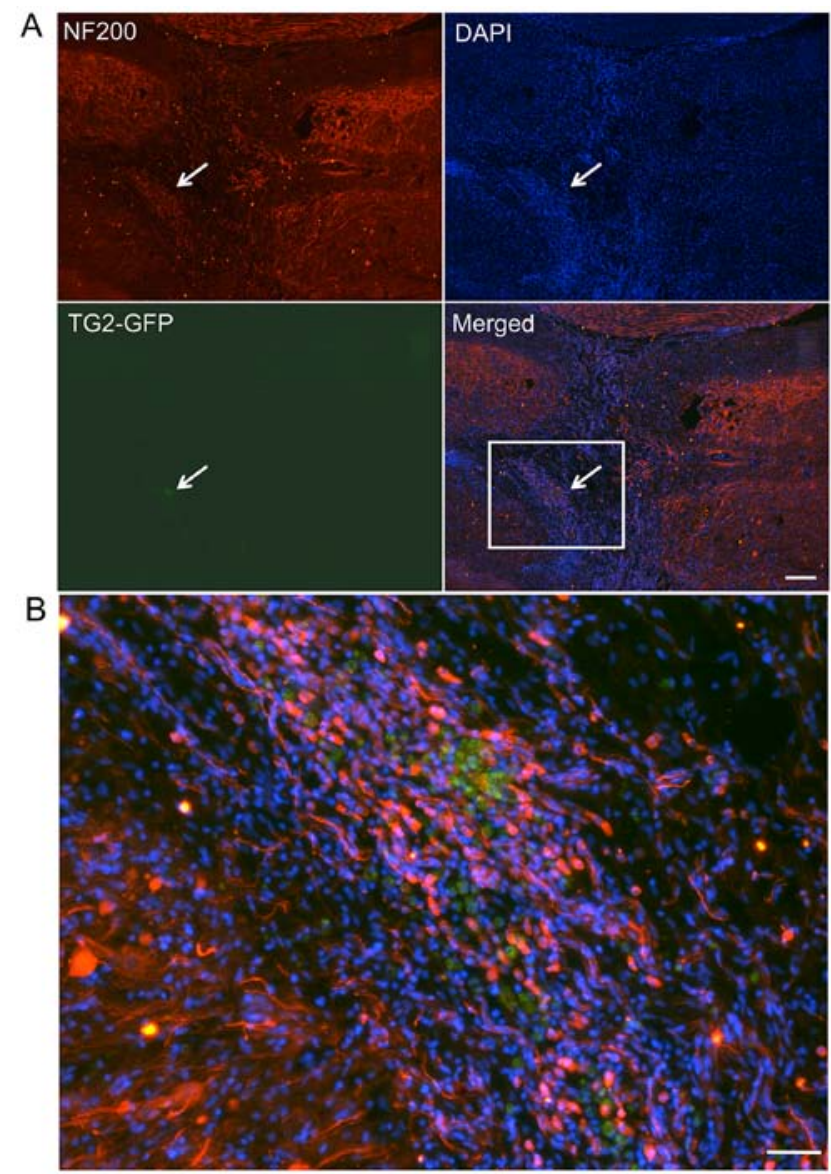

Figure 7. Differentiation of transplanted TG2-EMSCs to the lesion site of SCI. (A) Representative longitudinal sections showing NF-200 ${ }^{+}$cells (red) co-localized with GFP+EMSCs (green) in the SCI lesion site at two weeks. Scale bar, $500 \mu \mathrm{m}$. (B) An enlarged image of the insert in (A). Scale bar, $200 \mu \mathrm{m}$. EMSCs, ectomesenchymal stem cells; GFP, green fluorescent protein; NF-200, neurofilament-200; SCI, spinal cord injury; TG2, transglutaminase type 2 .

The results demonstrated that NF-200 ${ }^{+}$cells (Fig. 7) and Tuj- $1^{+}$ cells (Fig. 8) were co-localized with GFP+EMSCs (green) in the SCI lesion of rats that were transplanted with TG2-EMSCs. These findings indicated that TG2-EMSCs may differentiate into neurons in vivo.

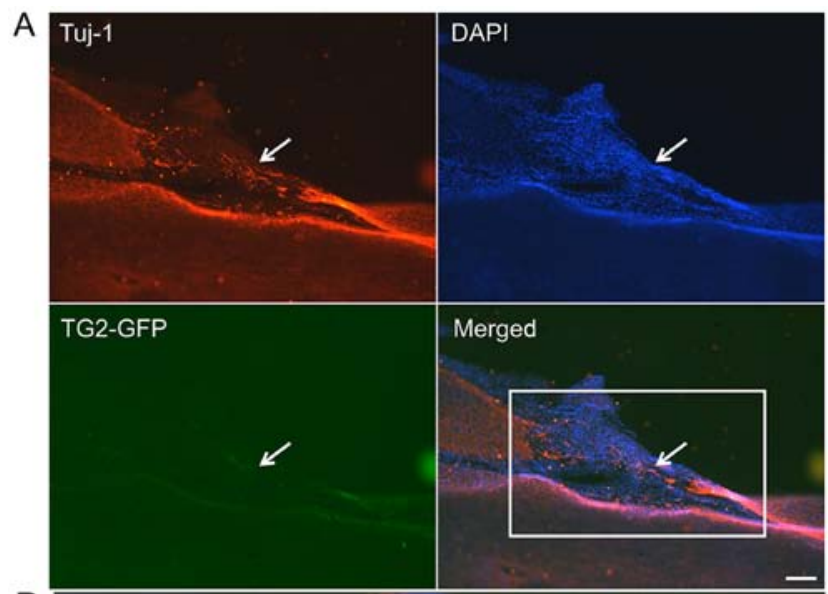

B

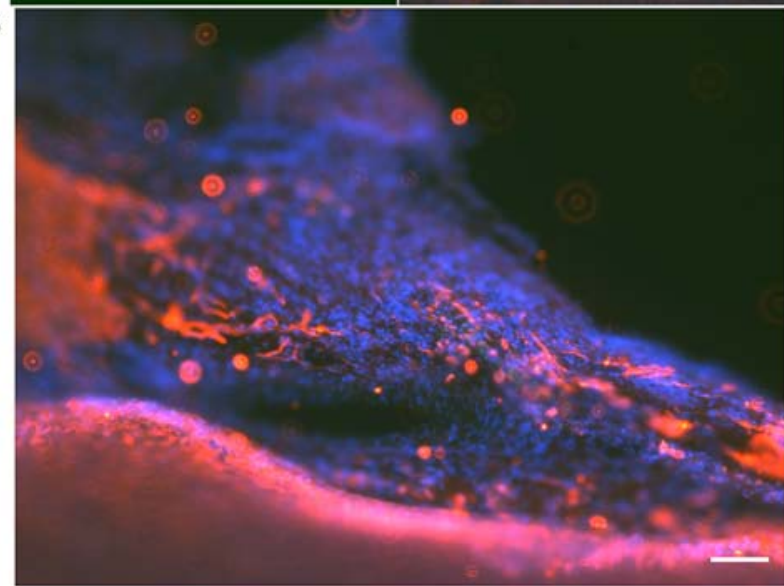

Figure 8. Differentiation of transplanted TG2-EMSCs to the lesion site of SCI. (A) Representative longitudinal sections showing Tuj- $1^{+}$cells (red) co-localized with GFP+EMSCs (green) in the SCI lesion site at two weeks. Scale bar, $500 \mu \mathrm{m}$. (B) An enlarged image of the insert in (A). Scale bar, $200 \mu \mathrm{m}$. EMSCs, ectomesenchymal stem cells; GFP, green fluorescent protein; SCI, spinal cord injury; TG2, transglutaminase type 2 ; Tuj-1, $\beta$ III tubulin.

TG2-EMSCs transplantation promotes rats functional recovery following SCI. BBB and Grid-walk analyses were performed to determine the effect of TG2-EMSCs transplantation in rats on functional recovery following SCI. One week following injury, the average $\mathrm{BBB}$ score of the three groups was $2.33 \pm 0.35$. At 
A

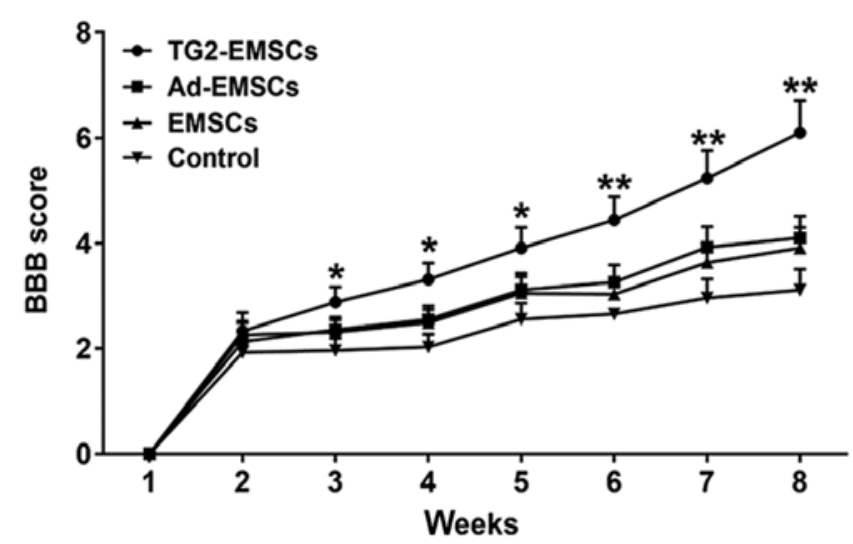

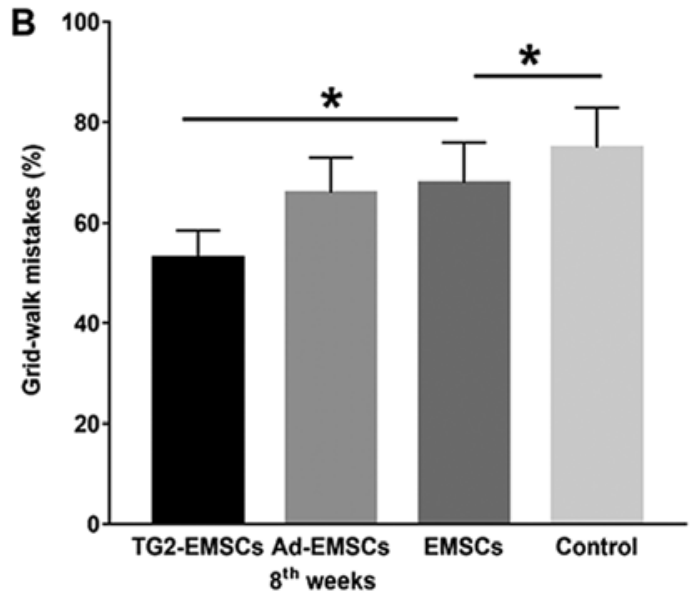

Figure 9. TG2-EMSCs transplantation improves locomotor recovery following SCI. (A) Rats transplanted with TG2-EMSCs exhibited significant improvements in locomotor BBB score at three weeks that persisted through to week 8 when compared with the controls group $\left(\mathrm{n}=6\right.$; ${ }^{*} \mathrm{P}<0.05$ and $\left.{ }^{* * *} \mathrm{P}<0.01\right)$. (B) The TG2-EMSCs transplantation group had fewer footfall errors in the Grid-walk analysis than control animals eight weeks post-transplantation. "P $<0.05$, as indicated. Ad, adenovirus; BBB, Basso, Beattie, and Bresnahan; EMSCs, ectomesenchymal stem cells; SCI, spinal cord injury; TG2, transglutaminase type 2.

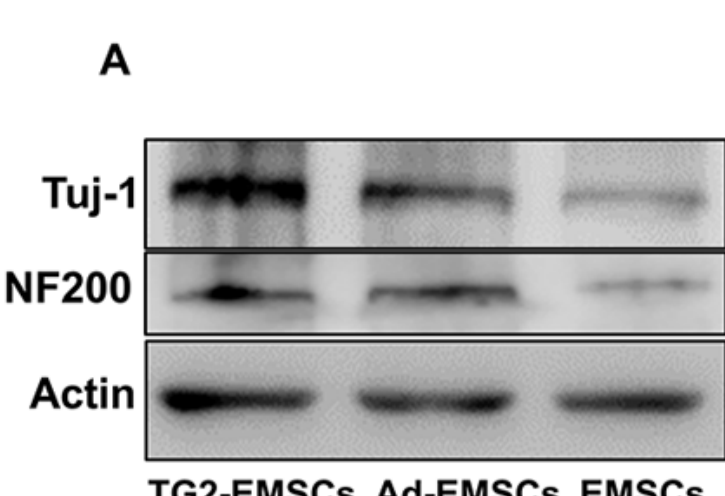

TG2-EMSCs Ad-EMSCs EMSCs

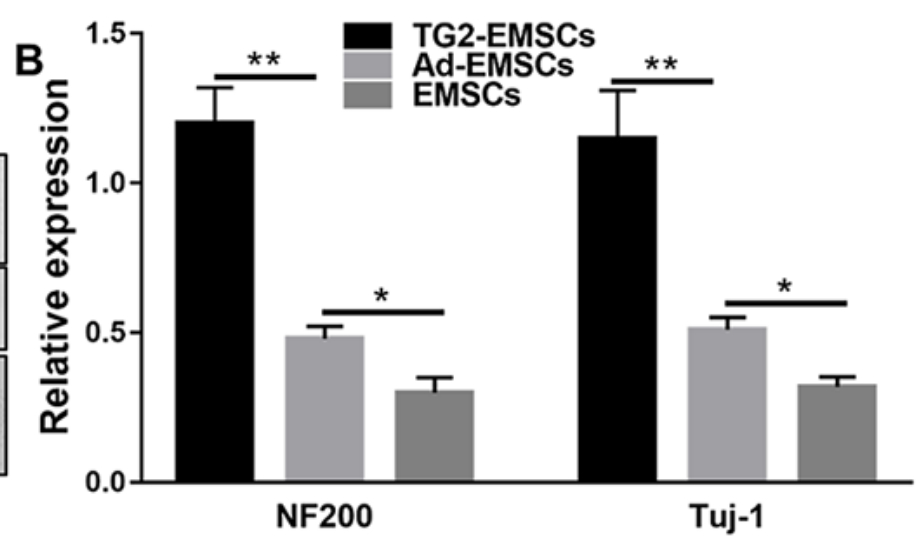

Figure 10. Higher expression of NF-200 and Tuj-1 in the TG2-EMSCs group was demonstrated by western blotting. (A) Western blotting of NF-200 and Tuj-1 expression levels. (B) Western blotting quantification. Data represent the mean \pm standard deviation of measurements made from three replicates. ${ }^{*} \mathrm{P}<0.05$ and ${ }^{* *} \mathrm{P}<0.01$, as indicated. Ad, adenovirus; EMSCs, ectomesenchymal stem cells; NF-200, neurofilament-200; TG2, transglutaminase type 2; Tuj-1, $\beta$ III tubulin.

4 weeks following TG2-EMSCs transplantation, there was no significant difference in BBB scores between groups. However, rats transplanted with TG2-EMSCs presented a significant improvement in the BBB score during continued recovery compared with the control group (Fig. 9A). In addition, rats were assessed by a Grid-walk test 8 weeks following transplantation. Compared with the EMSCs- or Ad-EMSCs-transplanted groups, rats that were transplanted with TG2-EMSCs exhibited a reduced number of footprint errors (Fig. 9B).

NF-200 and Tuj-1 expression and EMSC survival. As presented in Fig. 10, western blotting demonstrated that the NF-200 and Tuj-1 axonal markers were expressed in the lesion. At eight weeks post-operation, NF-200 and Tuj-1 expression significantly higher in the TG2-EMSC group compared with the control group. These results suggested that TG2-EMSCs may enhance axonal regeneration.

TG2-EMSC transplantation increases tissue sparing in rats following SCI. To determine whether TG2-EMSC transplantation can increase tissue retention, the gross morphology of the injured spinal cord was examined at 8 weeks following transplantation. As presented in Fig. 11, the results indicated that TG2-EMSCs transplantation markedly decreased the lesion volume compared with the control groups.

\section{Discussion}

Central nervous system (CNS) damage invariably leads to severe dysfunction. This is due to permanent nerve tissue damage caused by the neuron's inability to regenerate effectively (26). At present, the efficacy of available treatments remains largely unsatisfactory. However, thanks to advances in stem cell transplantation therapies, the situation is gradually improving as increasing evidence suggests that the treatment of traumatic nervous system damage is possible (27-29). Notably, the type of cell chosen is critical for the therapy efficacy. The present study used EMSCs because they present stem cell characteristics, including nestin, vimentin, S100 and CD133 expression, which may increase neuronal survival rate and axon length. In cases of injured CNS, EMSC transplantation has been reported to improve functional recovery following traumatic SCI $(25,30)$. 

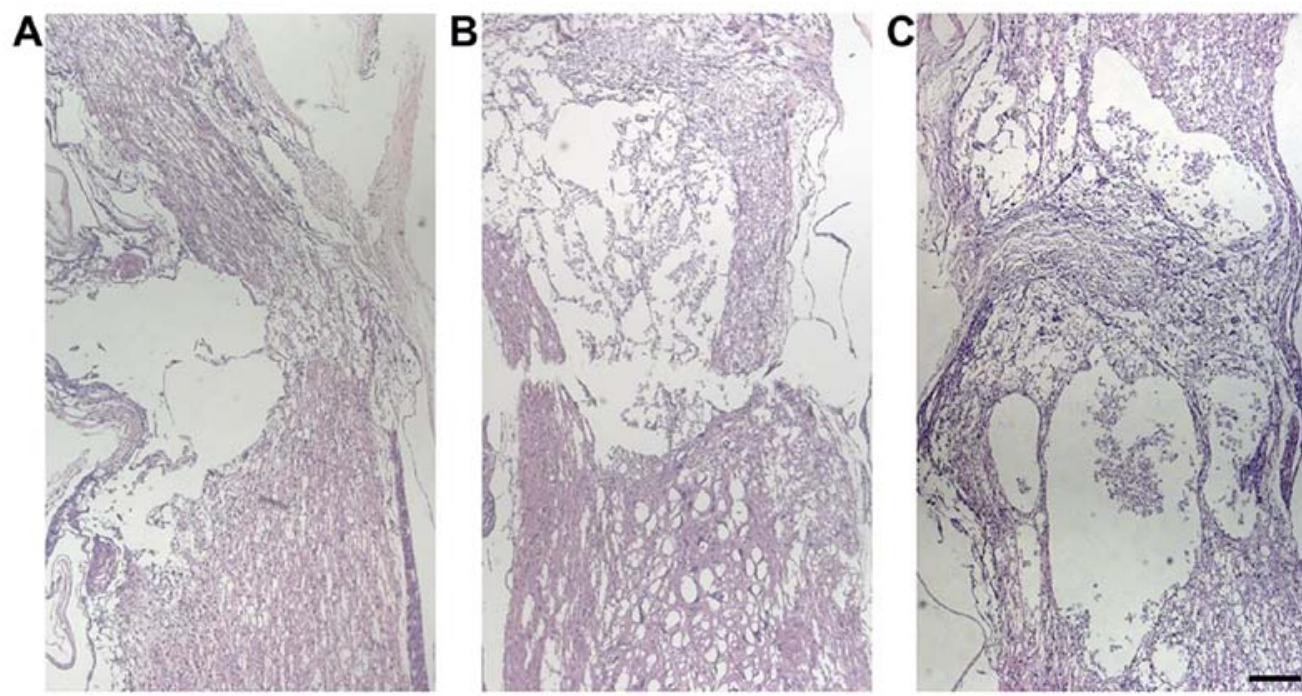

Figure 11. Tissue sparing in the spinal cord following spinal cord injury. Representative images of sections hematoxylin and eosin-stained showing the extent of tissue sparing at the lesion center eight weeks post-transplantation: (A) transglutaminase type 2-EMSCs group, (B) adenovirus-EMSCs group and (C) EMSCs group. EMSCs, ectomesenchymal stem cells.

Previous studies from our laboratory demonstrated that EMSCs can significantly promote the transformation of oligodendrocyte precursor cells into oligodendrocytes, and to stimulate oligodendrocyte processes and mature growth in vitro $(4,25,31)$. Furthermore, EMSCs are a source of numerous trophic molecules, including NGF, NT3 and BDNF, which provide essential support to the CNS following injury, and may therefore serve a crucial role in CNS regeneration $(24,25,31)$. These findings suggest that EMSCs may constitute a valuable cell source for the treatment of neurological diseases.

EMSCs are pluripotent adult stem cells derived from cranial neural crest that have a strong tendency to differentiate into neurons $(4,6,25,31)$. Vanella et al (32) reported that TG2 is increased during neuronal differentiation in human MSCs, which suggests that TG2 could serve a key role in the biochemical pathway involved in the differentiation of human MSCs in neural cells and that TG2 may be a part of downstream events associated with the neural differentiation of MSCs. In the present study, EMSCs overexpressing TG2 were designed to examine the effects of endogenous TG2 on neural cell proliferation and differentiation. The results demonstrated that high levels of TG2 were detected by western blotting without altering cell morphology. In addition, the results from immunofluorescence staining revealed a higher percentage of $\mathrm{Ki}-67^{+}$cells in the TG2-EMSC group compared with control groups, which were confirmed by the results of the MTT assay and cell count. Furthermore, the EMSC-induced differentiation into neurons was more efficient in the TG2-EMSC group than in the control groups. For instance, EMSCs revealed neuron-shaped and polygonal morphology, which was further confirmed by GAP-43, Tuj-1 and MAP2 antigenic markers $(33,34)$. In addition, western blotting results indicated that the expression levels of GAP-43, Tuj-1 and MAP2 were significantly increased in TG2-EMSCs in vitro.

TG2 is well known to interact non-covalently with the ubiquitous and abundant ECM in vitro $(35,36)$. Previous studies demonstrated the ability of cell-surface TG2 to bind to soluble proteins of the ECM, including FN and LN, and to promote
ECM deposition $(37,38)$. The present study demonstrated that the expression levels of FN and LN were significantly higher in the TG2-EMSC group compared with the control groups. We therefore hypothesized that deposited ECM may promote EMSCs proliferation by providing strong biological stimuli, including arginine-glycine-aspartic acid (RGD) sequences contained in the ECM (39). However, numerous studies have reported that EMSCs isolated and cultured in vitro can secrete various neurotrophic factors, including NGF, NT-3 and BDNF, which serve crucial roles in neural cell growth, proliferation and differentiation $(40,41)$. However, these soluble neurotrophic factors are rapidly cleared in vivo and in vitro (42), which might explain the weaker cell proliferation and differentiation rates observed in the control groups. Conversely, more neurotrophins were detected in the TG2-EMSC group compared with the control groups. These interesting results are reminiscent of the soluble neurotrophic factors cross-linked by TG2. Increasing evidence suggests that TG2 could cross-link cytokines without losing biological activity $(10,14)$. Taken together, the results from the present study demonstrated that TG2 overexpression promoted EMSC proliferation and enhanced EMSC differentiation into neurons by facilitating ECM deposition and cross-linking endogenous neurotrophic factors.

Although the safety of cell-based gene therapy has not been firmly established, TG2-EMSCs did not cause tumor formation within eight weeks following transplantation in rats. Conversely, TG2-EMSCs-transplanted rats presented more nerve fibers than rats from the control groups. NF-200 and Tuj-1 are considered to be markers of axons. The present study revealed that the TG2-EMSCs-transplanted group had higher NF-200 and Tuj-1 expression compared with control groups. These neuron-associated proteins may be derived from the differentiation of endogenous neural stem cells, and TG2-EMSCs may form a microenvironment that facilitates nerve regeneration at the site of SCI. Another possible source of nerve fibres was via replenishment of the degenerated nerve fibers by the neurons directly differentiated from TG2-EMSCs. The results from immunofluorescence staining demonstrated that TG2-EMSCs 
could survive for four weeks and presented neuron-like phenotypes and morphologies following SCI.

By promoting the expression of neurotrophins and ECM (FN and LN), TG2-EMSCs may improve the neuroregeneration microenvironment in spinal cord lesions and enhance functional recovery. Increasing evidence reports that neurotrophins can significantly promote neurogenesis and contribute to neuroplasticity and functional recovery following SCI. Stable neurotrophic effects may therefore partially explain the axonal regeneration and functional recovery observed in the present study. The Grid-walk score assesses voluntary movements controlled by dorsal descending tracts. Improvements in hindlimb performance are important, as the four-point increase in the BBB score reveals (43). In the present study, the BBB and Grid-walk scores of rats from the TG2-EMSC group exhibited a significant improvement compared with rats in the control groups. Previous studies demonstrated that EMSC treatment can significantly improve functional recovery rats following SCI $(4,6,25,31)$. In the present study, the TG2-EMSC group had more trophic factors, ECM, and axon regeneration. The results revealed that TG2-EMSCs may enhance the functional recovery of rats following SCI. Recent studies reported that TG2 is closely associated with NF- $\kappa \mathrm{B}$ signaling pathway $(44,45)$. Since TG2 might enhance EMSC quality and promote SCI repair by activating the $\mathrm{NF}-\kappa \mathrm{B}$ signaling pathway, future investigations are required to provide novel information about the therapeutic potential of TG2 in SCI.

In conclusion, the present study demonstrated that EMSCs overexpressing TG2 may promote functional recovery following SCI through complex processes. Further investigation is needed to fully understand the underlying mechanisms of TG2-associated protection against SCI.

\section{Acknowledgements}

Not applicable.

\section{Funding}

The present study was funded by the National Natural Science Foundation of China (grants no. 81571830 and 81501077), the Jiangsu Provincial Development Fund Project (Clinical Application of 3D Printing Technology in Complex Pelvic Fractures; grant no. YKK16228) and the Clinical Access Development Fund of Jiangsu University School of Medicine (Digital Study of Anatomical Reconstruction of the Clavicular Canal of the Tibial Ligament; grant nos. JLY20180040 and JLY20160185).

\section{Availability of data and materials}

All data generated or analyzed during the present study were included in this published article.

\section{Authors' contributions}

WS and ZZ conceived and designed the study. DL, SB and ZX performed the experiments. YQ and DW wrote the manuscript and contributed to the analysis or interpretation of the data. All authors have read and approved the final manuscript and agreed to be accountable for all aspects of the research in ensuring that the accuracy and integrity of any part of the work are appropriately investigated and resolved.

\section{Ethics approval and consent to participate}

All animal procedures were approved by the Jiangsu University School of Medicine and Gaochun People's Hospital Animal Experiment Committee.

\section{Patient consent for publication}

Not applicable.

\section{Competing interests}

The authors declare that they have no competing interests.

\section{References}

1. Jin MC, Medress ZA, Azad TD, Doulames VM and Veeravagu A: Stem cell therapies for acute spinal cord injury in humans: A review. Neurosurgical Focus 46: E10, 2019.

2. Konig N, Trolle C, Kapuralin K, Adameyko I, Mitrecic D, Aldskogius H, Shortland PJ and Kozlova EN: Murine neural crest stem cells and embryonic stem cell-derived neuron precursors survive and differentiate after transplantation in a model of dorsal root avulsion. J Tissue Eng Regen Med 11: 129-137, 2017.

3. Richardson SM,Kalamegam G, Pushparaj PN, Matta C,Memic A, Khademhosseini A, Mobasheri R, Poletti FL, Hoyland JA and Mobasheri A: Mesenchymal stem cells in regenerative medicine: Focus on articular cartilage and intervertebral disc regeneration. Methods 99: 69-80, 2016.

4. Zhang Z, He Q, Deng W, Chen Q, Hu X, Gong A, Cao X, Yu J and Xu X: Nasal ectomesenchymal stem cells: Multi-lineage differentiation and transformation effects on fibrin gels. Biomaterials 49: 57-67, 2015.

5. Liu J, Chen Q, Zhang Z, Zheng Y, Sun X, Cao X, Gong A, Cui Y, He Q and Jiang P: Fibrin scaffolds containing ectomesenchymal stem cells enhance behavioral and histological improvement in a rat model of spinal cord injury. Cells Tissues Organs 198: 35-46, 2013.

6. Zhang J, Gao X, Zou H, Liu J and Zhang Z: Rat nasal respiratory mucosa-derived ectomesenchymal stem cells differentiate into schwann-like cells promoting the differentiation of PC12 cells and forming myelin in vitro. Stem Cells Int 2015: 328957, 2015.

7. Abdallah B and Kassem M: Human mesenchymal stem cells: From basic biology to clinical applications. Gene Ther 15: 109-116, 2008.

8. Sahni V and Kessler JA: Stem cell therapies for spinal cord injury. Nat Rev Neurol 6: 363-372, 2010.

9. Badarau E, Collighan RJ and Griffin M: Recent advances in the development of tissue transglutaminase (TG2) inhibitors. Amino Acids 44: 119-127, 2013.

10. Belkin AM: Extracellular TG2: Emerging functions and regulation. FEBS J 278: 4704-4716, 2011.

11. Zemskov EA, Janiak A, Hang J, Waghray A and Belkin AM: The role of tissue transglutaminase in cell-matrix interactions. Front Biosci 11: 1057-1076, 2006.

12. Collighan RJ and Griffin M: Transglutaminase 2 cross-linking of matrix proteins: Biological significance and medical applications. Amino Acids 36: 659-670, 2009.

13. Kanchan K, Fuxreiter M and Fésüs L: Physiological, pathological, and structural implications of non-enzymatic protein-protein interactions of the multifunctional human transglutaminase 2 . Cell Mol Life Sci 72: 3009-3035, 2015.

14. Lorand L and Graham RM: Transglutaminases: Crosslinking enzymes with pleiotropic functions. Nat Rev Mol Cell Biol 4: 140-156, 2003.

15. Soluri MF, Boccafoschi F, Cotella D, Moro L, Forestieri G, Autiero I, Cavallo L, Oliva R, Griffin M, Wang Z, et al: Mapping the minimum domain of the fibronectin binding site on transglutaminase 2 (TG2) and its importance in mediating signaling, adhesion, and migration in TG2-expressing cells. FASEB J 33: 2327-2342, 2019. 
16. Tucholski J: TG2 protects neuroblastoma cells against DNA-damage-induced stress, suppresses p53 activation. Amino Acids 39: 523-532, 2010.

17. Van Strien ME, Drukarch B, Bol JG, van der Valk P, van Horssen J, Gerritsen WH, Breve JJ and van Dam AM: Appearance of tissue transglutaminase in astrocytes in multiple sclerosis lesions: A role in cell adhesion and migration? Brain Pathol 21: 44-54, 2011.

18. Pitolli C, Pietroni V, Marekov L, Terrinoni A, Yamanishi K, Mazzanti C, Melino G and Candi E: Characterization of TG2 and TG1-TG2 double knock-out mouse epidermis. Amino Acids 49: 635-642, 2017.

19. Ginn SL, Amaya AK, Alexander IE, Edelstein M and Abedi MR: Gene therapy clinical trials worldwide to 2017: An update. J Gene Med 20: e3015, 2018.

20. Qu Y, Zhao J, Wang Y and Gao Z: Silencing ephrinB3 improves functional recovery following spinal cord injury. Mol Med Rep 9: 1761-1766, 2014.

21. Ribault A, Loinard C, Flamant S, Lim S and Tamarat R: Exosomes derived from human mesenchymal stromal cells promote wound healing in a mouse model of radiation-induced injury. Cytotherapy 20: e2-e3, 2018.

22. Yuan X, Wu Q, Wang P, Jing Y, Yao H, Tang Y, Han R, He W, Li Z, Zhang H and Xiu R: Intraspinal administration of interleukin-7 promotes neuronal apoptosis and limits functional recovery through JAK/STAT5 pathway following spinal cord injury. Biochem Biophys Res Commun 514: 1023-1029, 2019.

23. Caglar YS, Demirel A, Dogan I, Huseynov R, Eroglu U, Ozgural O, Cansiz C, Bahadir B, Kilinc MC and Al-Beyati ESM: Effect of riluzole on spinal cord regeneration with hemisection method before injury. World Neurosurg 114: e247-e253, 2018.

24. Chen Q, Zhang Z, Liu J, He Q, Zhou Y, Shao G, Sun X, Cao X, Gong A and Jiang P: A fibrin matrix promotes the differentiation of EMSCs isolated from nasal respiratory mucosa to myelinating phenotypical schwann-like cells. Mol Cells 38: 221-228, 2015.

25. Deng W, Shao F, He Q, Wang Q, Shi W, Yu Q, Cao X, Feng C, Bi S, Chen J, et al: EMSCs Build an All-in-One niche via cell-cell lipid raft assembly for promoted neuronal but suppressed astroglial differentiation of neural stem cells. Adv Mater 31: e1806861,2019.

26. Egawa N, Lok J, Washida K and Arai K: Mechanisms of axonal damage and repair after central nervous system injury. Transl Stroke Res 8: 14-21, 2017.

27. Sun Y, Wu H, Chen G, Huang X, Shan Y, Shi H, Zhang Q and Zheng Y: Genetically engineered recombinant adenovirus expressing interleukin-2 for hepatocellular carcinoma therapy. Mol Med Rep 17: 300-306, 2018.

28. Sandner B, Ciatipis M, Motsch M, Soljanik I, Weidner N and Blesch A: Limited functional effects of subacute syngeneic bone marrow stromal cell transplantation after rat spinal cord contusion injury. Cell Transplant 25: 125-139, 2016

29. Li J, Guo W, Xiong M, Zhang S, Han H, Chen J, Mao D, Yu H and Zeng Y: Erythropoietin facilitates the recruitment of bone marrow mesenchymal stem cells to sites of spinal cord injury. Exp Ther Med 13: 1806-1812, 2017.

30. Ibarretxe G, Crende O, Aurrekoetxea M, García-Murga V, Etxaniz J and Unda F: Neural crest stem cells from dental tissues: A new hope for dental and neural regeneration. Stem Cells Int 2012: 103503, 2012.

31. Zhang Z, Li Z, Deng W, He Q, Wang Q, Shi W, Chen Q, Yang W, Spector M, Gong A, et al: Ectoderm mesenchymal stem cells promote differentiation and maturation of oligodendrocyte precursor cells. Biochem Biophys Res Commun 480: 727-733, 2016

32. Vanella L, Raciti G, Barbagallo I, Bonfanti R, Abraham N and Campisi A: Tissue transglutaminase expression during neural differentiation of human mesenchymal stem cells. CNS Neurol Disord Drug Targets 14: 24-32, 2015.
33. Hung CC, Lin CH, Chang H, Wang CY, Lin SH, Hsu PC, Sun YY, Lin TN, Shie FS, Kao LS, et al: Astrocytic GAP43 induced by the TLR4/NF- $\kappa$ B/STAT3 axis attenuates astrogliosis-mediated microglial activation and neurotoxicity. J Neurosci 36: 2027-2043, 2016.

34. Locatelli F, Corti S, Donadoni C, Guglieri M, Capra F, Strazzer S, Salani S, Del Bo R, Fortunato F, Bordoni A and Comi GP: Neuronal differentiation of murine bone marrow Thy-1- and Sca-1-positive cells. J Hematother Stem Cell Res 12: 727-734, 2003.

35. Stephens P, Grenard P, Aeschlimann P, Langley M, Blain E, Errington R, Kipling D, Thomas D and Aeschlimann D: Crosslinking and G-protein functions of transglutaminase 2 contribute differentially to fibroblast wound healing responses. J Cell Sci 117: 3389-3403, 2004.

36. Nelea V, Nakano Y and Kaartinen MT: Size distribution and molecular associations of plasma fibronectin and fibronectin crosslinked by transglutaminase 2. Protein J 27: 223-233, 2008.

37. Chau DY, Brown SV, Mather ML, Hutter V, Tint NL, Dua HS, Rose FR and Ghaemmaghami AM: Tissue transglutaminase (TG-2) modified amniotic membrane: A novel scaffold for biomedical applications. Biomed Mater 7: 045011, 2012.

38. Pavlyukov MS, Antipova NV, Balashova MV and Shakhparonov MI: Detection of transglutaminase 2 conformational changes in living cell. Biochem Biophys Res Commun 421: 773-779, 2012

39. Li J, Li X, Jing Z, Kawazoe N and Chen G: Induction of chondrogenic differentiation of human mesenchymal stem cells by biomimetic gold nanoparticles with tunable RGD density. Adv Healthc Mater: 6, 2017 doi: 10.1002/adhm.201700317.

40. Pollock K, Dahlenburg H, Nelson H, Fink KD, Cary W, Hendrix K, Annett G, Torrest A, Deng P, Gutierrez J, et al: Human mesenchymal stem cells genetically engineered to overexpress brain-derived neurotrophic factor improve outcomes in huntington's disease mouse models. Mol Ther 24: 965-977, 2016.

41. Barde YA, Edgar D and Thoenen H: Purification of a new neurotrophic factor from mammalian brain. EMBO J 1: 549-553, 1982.

42. Jia Y, Wu D, Zhang R, Shuang W, Sun J, Hao H, An Q and Liu Q: Bone marrow-derived mesenchymal stem cells expressing the Shh transgene promotes functional recovery after spinal cord injury in rats. Neurosci Lett 573: 46-51, 2014.

43. Mifflin KA, Frieser E, Benson C, Baker G and Kerr BJ: Voluntary wheel running differentially affects disease outcomes in male and female mice with experimental autoimmune encephalomyelitis. J Neuroimmunol 305: 135-144, 2017.

44. Jambrovics K, Uray IP, Keressztesy Z, Keillor JW, Fésüs L and Balajthy $Z$ : Transglutaminase 2 programs differentiating acute promyelocytic leukemia cells in all-trans retinoic acid treatment to inflammatory stage through NF-kB activation. Haematologica 104: 505-515, 2019.

45. Feola J, Barton A, Akbar A, Keillor J and Johnson GVW: Transglutaminase 2 modulation of NF- $\mathrm{kB}$ signaling in astrocytes is independent of its ability to mediate astrocytic viability in ischemic injury. Brain Res 1668: 1-11, 2017.

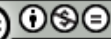

This work is licensed under a Creative Commons Attribution-NonCommercial-NoDerivatives 4.0 International (CC BY-NC-ND 4.0) License. 